\title{
CAPACITATION OF EPIDIDYMAL SPERMATOZOA IN A MEDIUM WITH HIGH K/Na RATIO AND CYCLIC AMP FOR THE FERTILIZATION OF RAT EGGS IN VITRO
}

\author{
Y. TOYODA* AND M. G. GHANG \\ Worcester Foundation for Experimental Biology, Shrewsbury, \\ Massachusetts 01545, U.S.A.
}

(Received 22nd January 1973)

\begin{abstract}
Summary. Spermatozoa from the cauda epididymidis of adult male rats were preincubated in different media for various times and used for fertilization in vitro. When examined at different times after insemination, sperm penetration occurred 5 to $6 \mathrm{hr}$ after insemination with epididymal spermatozoa preincubated in a standard medium as used for fertilization, and a marked decrease of penetration rates was observed if the preincubation period exceeded $3 \mathrm{hr}$. Addition of rat serum to the standard medium did not improve the time and rate of sperm penetration. By contrast, preincubation of spermatozoa in the presence of $2 \mathrm{~mm}$ dibutyryl cyclic $3^{\prime}, 5^{\prime}$-adenosine monophosphate (dCAMP) caused earlier sperm penetration although the overall penetration rates decreased as the time of preincubation increased. Preincubation of spermatozoa in a medium with a high potassium/sodium ratio $(0.32)$ increased the penetration rates and caused early sperm penetration, while in a medium containing high $\mathrm{K} / \mathrm{Na}$ ratio and $2 \mathrm{~mm}$-dCAMP the latency of sperm penetration was shortened distinctively and approximately $90 \%$ of eggs were penetrated within $3 \mathrm{hr}$ after insemination with spermatozoa preincubated for 5 to $6 \mathrm{hr}$. It is considered that rat epididymal spermatozoa can be capacitated in a chemically defined medium and that addition of potassium and/or dCAMP accelerates the process of capacitation.
\end{abstract}

\section{INTRODUGTION}

The recent achievement of fertilization in vitro by epididymal spermatozoa of the hamster (Yanagimachi \& Chang, 1964)), mouse (Iwamatsu \& Chang, 1969), guinea-pig (Yanagimachi, 1972) and rat (Toyoda \& Chang, 1974) has made it possible to analyse the necessary conditions for the capacitation of spermatozoa in a defined physico-chemical environment. In the hamster and mouse, it has been shown that epididymal spermatozoa can be better capacitated in vitro in the presence of follicular fluid or blood serum (Barros \& Austin, 1967; Yanagimachi, 1969, 1970; Barros \& Garavagno, 1970; Iwamatsu \&

* Present address: Department of Animal Science, Kitasato University, Towada, Aomori 034, Japan. 
Chang, 1969, 1970). The induction of capacitation in these experiments was recognized physiologically by the shortening of the latency for sperm penetration and morphologically by the loss of acrosomes in the preincubated spermatozoa. In the hamster and mouse, the functional change can be induced in a chemically defined medium without any supplementation of blood serum or reproductive-tract fluids (Bavister, 1969; Toyoda, Yokoyama \& Hosi, 1971 ; Miyamoto \& Chang, 1972). This has also been shown for the epididymal spermatozoa of the guinea-pig (Yanagimachi, 1972). In the rat, the capacitation of spermatozoa in the female tract has been clearly demonstrated (Austin, 1951a; Noyes, 1953) and it would be of interest to know whether the epididymal spermatozoa of this species can be capacitated in vitro in a chemically defined medium and whether addition of other substances can accelerate this process.

\section{MATERIALS AND METHODS}

Recently ovulated eggs were obtained from immature female rats (22 to 25 days old) of Sprague-Dawley strain (Charles River CD) that had been injected subcutaneously with 10 i.u. PMSG and 40 to $48 \mathrm{hr}$ later with 10 i.u. HCG intraperitoneally. They were killed 13 to $17 \mathrm{hr}$ after the injection of HCG. The standard medium for the preincubation of spermatozoa and for fertilization of the eggs in vitro was a modified Krebs-Ringer bicarbonate solution (Toyoda \& Chang, 1974) which was essentially the same as the medium developed for culturing mouse oocytes (Biggers, Whitten \& Whittingham, 1970). The total concentrations of sodium and potassium ions in this medium were 141.75 and 6.17 mequiv., respectively. Eggs were dissected from the oviducts and placed in $0.4 \mathrm{ml}$ standard medium which had been covered with paraffin oil and kept in a $\mathrm{CO}_{2}$ incubator $\left(5 \% \mathrm{CO}_{2}\right.$ in air at $\left.37^{\circ} \mathrm{C}\right)$.

Spermatozoa obtained from the cauda epididymidis of mature male rats of the same strain were preincubated in a particular medium. The volume of medium was $0.5 \mathrm{ml}$ and the concentration of spermatozoa was between 3 and 6 $\times 10^{6} / \mathrm{ml}$. The following media were used. (a) The same medium as that for fertilization (standard medium). (b) The standard medium supplemented with $20 \%$ rat serum. The serum was obtained from blood collected by heart puncture from mature female rats and allowed to clot at room temperature and then centrifuged. It was heated at $56^{\circ} \mathrm{C}$ for 35 to $45 \mathrm{~min}$ before use. (c) The standard medium supplemented with 2 mm-N ${ }^{6}, 2^{\prime}$-0-dibutyryl cyclic $3^{\prime}, 5^{\prime}$-adenosine monophosphate (dCAMP, sodium salt, Sigma Chemical Co.). This compound was dissolved in the medium just before use. (d) The standard medium containing a high potassium/sodium ratio, that is, the concentration of $\mathrm{KCl}$ was increased from 4.78 to $34.78 \mathrm{~mm}$ and that of $\mathrm{NaCl}$ was reduced from 94.6 to $64.6 \mathrm{~mm}$. Consequently, the $\mathrm{K} / \mathrm{Na}$ ratio in this medium was 0.32 instead of 0.043 in the standard medium. (e) The medium with high $\mathrm{K} / \mathrm{Na}$ ratio supplemented with 2 mM-dCAMP.

Epididymal spermatozoa suspended in different media covered with paraffin oil were kept in a $\mathrm{CO}_{2}$ incubator for $\frac{1}{2}, 3$ or $5 \frac{1}{2} \mathrm{hr}$. At the end of preincubation, $0.04 \mathrm{ml}$ sperm suspension was added to $0.4 \mathrm{ml}$ standard medium containing 
eggs, and the mixture was incubated again in a $\mathrm{CO}_{2}$ incubator. At $3,4,5$ to 6 or 7 to $8 \mathrm{hr}$ after insemination, some of the eggs, usually ten to fifteen, were picked up from the medium. They were placed in the centre of four vaseline spots on a slide, compressed with a coverslip and examined under a phasecontrast microscope for the assessment of sperm penetration. Solutions of $2.5 \%$ glutaraldehyde in phosphate buffer $(\mathrm{pH} \mathrm{7.4)}$ followed by $10 \%$ neutral formalin were used as fixatives. After staining with lacmoid, the eggs were again examined for morphological details. The sperm head was considered to have developed into a male pronucleus when primary nucleoli were observed in the enlarged head. At least three tests (usually five to seven) were performed for each experimental group and the proportions of penetrated eggs were compared statistically according to $\chi^{2}$ test.

\section{RESULTS}

In all the preincubation media tested, spermatozoa showed more than $70 \%$ active progressive motility in every trial throughout the preincubation period. At the beginning of incubation, spermatozoa showed more vigorous motility in the presence of blood serum, but there was hardly any difference among various preincubation media after prolonged incubation.

From the results presented in Table 1, it can be seen that the preincubation of spermatozoa in the standard medium did not induce an advancement of sperm penetration and, in fact, the preincubation for a longer time caused a marked reduction of the penetration rate. This was shown by the following facts. Of 247 eggs examined $4 \mathrm{hr}$ after insemination, only one egg from each group inseminated with spermatozoa preincubated for 3 or $5 \frac{1}{2} \mathrm{hr}$ was found with a spermatozoon in its perivitelline space. The rest had not been penetrated. At 5 to $6 \mathrm{hr}$ after insemination, $54.2,36.4$ and $4.5 \%$ of eggs were penetrated, respectively, by spermatozoa preincubated for $\frac{1}{2}, 3$ and $5 \frac{1}{2} \mathrm{hr}$. The enlargement of the sperm head was seen in the majority of penetrated eggs, but male pronuclei were observed in only two eggs at this time. Similarly, at 7 to $8 \mathrm{hr}$ after insemination, $89.5,34.6$ and $7.7 \%$ of eggs were penetrated, respectively, by spermatozoa preincubated for $\frac{1}{2}, 3$ and $5 \frac{1}{2} \mathrm{hr}$. Thus, the penetration rates decreased as the time of preincubation increased in both cases. The difference of penetration rates between samples preincubated for various times were highly significant $(P<0.01)$. Male pronuclei were observed in 38 to $44 \%$ of penetrated eggs.

In those eggs inseminated with spermatozoa preincubated in the presence of blood serum, the penetration rates were also low (2 to $3 \%$ ) at $4 \mathrm{hr}$ after insemination. In a group of eggs inseminated with spermatozoa preincubated for $\frac{1}{2} \mathrm{hr}$, the penetration rates increased from 2 to $47.2 \%$ when examined between 4 and 7 to $8 \mathrm{hr}$ after insemination although at 7 to $8 \mathrm{hr}$ after insemination, the percentage $(47.2 \%)$ was significantly lower than that $(89.5 \%)$ of eggs which had been inseminated with spermatozoa preincubated for 30 min without serum. In the group of eggs inseminated with spermatozoa preincubated in the presence of serum for $5 \frac{1}{2} \mathrm{hr}$, the penetration rates remained low (15 to $18 \%$ ) in spite of the ionger time after insemination ( 5 to $8 \mathrm{hr}$ ).

Preincubation of spermatozoa for $30 \mathrm{~min}$ in the presence of 2 mM-dCAMP 


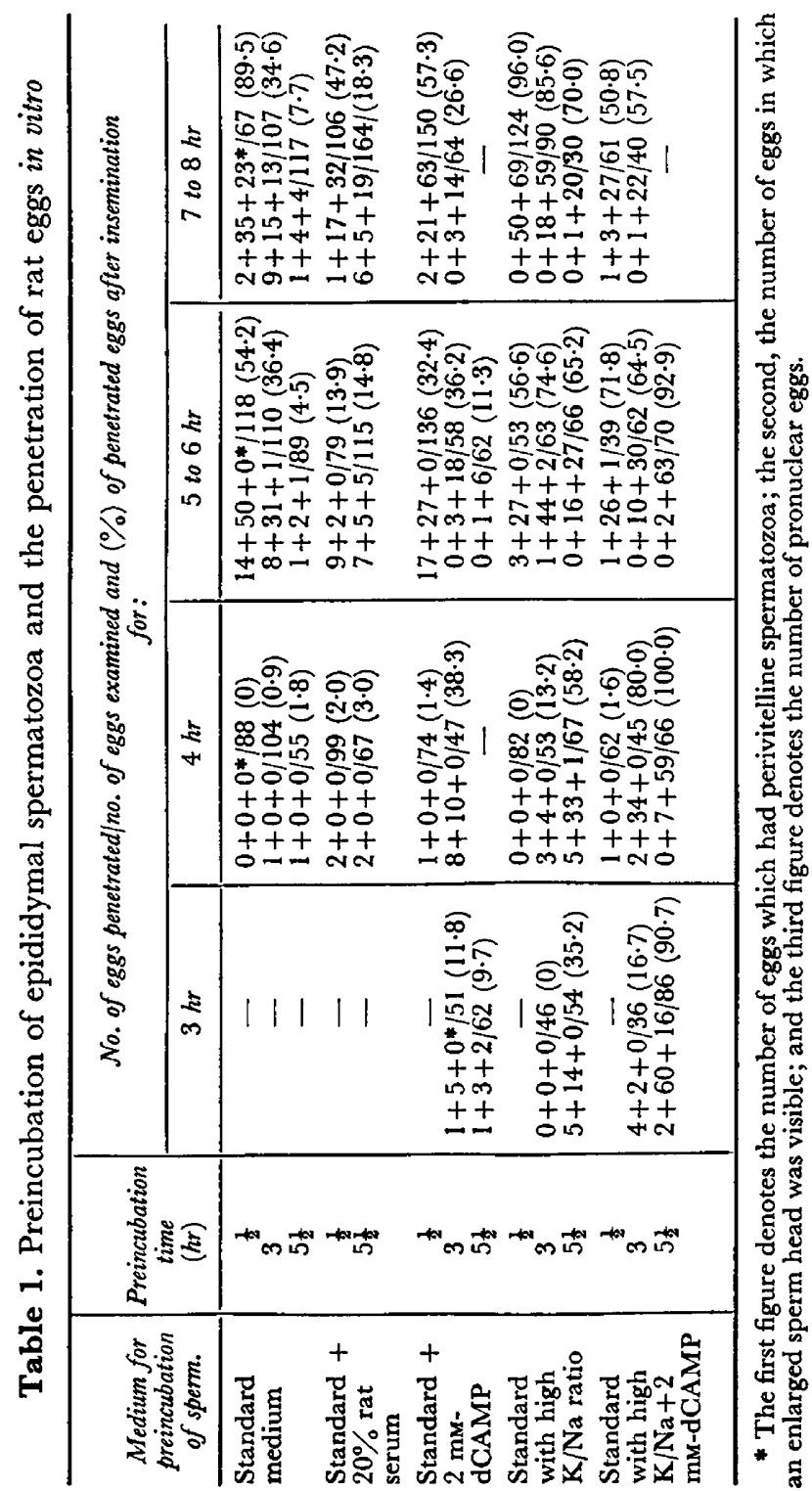


did not show any favourable effect on sperm penetration when examined $4 \mathrm{hr}$ after insemination. At 7 to $8 \mathrm{hr}$ after insemination, the penetration rate was lower $(57.8 \%)$ than those eggs inseminated with spermatozoa preincubated in the standard medium without dCAMP for $\frac{1}{2} \mathrm{hr}(89.5 \%)$. However, spermatozoa preincubated in the presence of dCAMP for $3 \mathrm{hr}$ penetrated the eggs in a short time. Six $(12 \%)$ of fifty-one and eighteen $(38 \%)$ of forty-seven eggs were penetrated at 3 and $4 \mathrm{hr}$ after insemination, respectively. The penetration rate at $4 \mathrm{hr}$ after insemination $(38 \%)$ was significantly higher $(P<0.01)$ than that of preceding groups ( 0 to $3 \%)$. The penetration rates, however, did not increase when the eggs were examined 5 to 6 or 7 to $8 \mathrm{hr}$ after insemination (36.2 or $26 \cdot 6 \%$ ), but the male pronuclei appeared earlier; eighteen of twenty-one penetrated eggs had male pronuclei by 5 to $6 \mathrm{hr}$ after insemination. Of sixtytwo eggs examined $3 \mathrm{hr}$ after insemination with $5 \frac{1}{2}$-hr preincubated spermatozoa, six $(9.7 \%)$ were penetrated and male pronuclei had already formed in two of them.

Preincubation of spermatozoa in a medium with a high $\mathrm{K} / \mathrm{Na}$ ratio resulted in an overall increase in the penetration rate. At the end of 7 to $8 \mathrm{hr}$ after insemination, $96 \cdot 0,85 \cdot 6$ and $70.0 \%$ of eggs were penetrated, respectively, by $\frac{1}{2}-, 3$ - and $5 \frac{1}{2}$-hr preincubated spermatozoa. The last two percentages $(85.6$ and $70.0 \%)$ were significantly higher $(P<0.01)$ than the corresponding percentages of the preceding experimental groups. It was also observed that the time of sperm penetration became shorter with increased periods of preincubation. While none of eighty-two eggs were penetrated within $4 \mathrm{hr}$ after insemination with $\frac{1}{2}$-hr preincubated spermatozoa, seven $(13.2 \%)$ of fifty-three eggs were penetrated at that time when spermatozoa preincubated for $3 \mathrm{hr}$ were used for insemination. Spermatozoa preincubated for $5 \frac{1}{2} \mathrm{hr}$ penetrated $35 \%$ of eggs within $3 \mathrm{hr}$ after insemination, but none of forty-six eggs was penetrated by 3-hr preincubated spermatozoa within this time. The development of a male pronucleus also occurred earlier in the eggs penetrated by spermatozoa preincubated for a longer time.

Finally, preincubation of spermatozoa in a medium containing 2 mM-dCAMP and high $\mathrm{K} / \mathrm{Na}$ ratio resulted in a most pronounced effect. Preincubation of spermatozoa in this medium for $30 \mathrm{~min}$ did not cause noticeable advancement of sperm penetration and the penetration at 7 to $8 \mathrm{hr}$ after insemination was also lower $(50.8 \%$ ) as compared to the experimental group preincubated without dCAMP but with high $\mathrm{K} / \mathrm{Na}$ ratio $(96.0 \%)$. However, preincubation for a longer period caused marked advancement of the sperm penetration. Spermatozoa preincubated for $3 \mathrm{hr}$ penetrated $16.7 \%$ and $80 \%$ of eggs within 3 and $4 \mathrm{hr}$ after insemination, respectively. When spermatozoa were preincubated for $5 \frac{1}{2} \mathrm{hr}$ before insemination, seventy-eight of eighty-six $(90.7 \%)$ eggs were penetrated within $3 \mathrm{hr}$ and the male pronuclei had already formed in sixteen eggs. All sixty-six eggs examined $4 \mathrm{hr}$ after insemination were also undergoing fertilization and fifty-nine $(89 \%)$ of them had well-formed male pronuclei.

In this experimental group where spermatozoa were preincubated in a medium with high $\mathrm{K} / \mathrm{N}$ aand dGAMP for $5 \frac{1}{2} \mathrm{hr}$, an additional twenty eggs were examined at $2 \mathrm{hr}$ after insemination. Fifteen eggs $(75 \%)$ were penetrated and 
thirteen of them $(65 \%)$ were undergoing fertilization. Another forty-six eggs were examined at 22 or $30 \mathrm{hr}$ after insemination in order to determine whether the eggs which had been penetrated earlier could accomplish the final stage of fertilization. Of twelve eggs examined $22 \mathrm{hr}$ after insemination, four were at the late pronuclear stage and eight were between prophase and anaphase of first cleavage. Thirty (88\%) of thirty-four eggs examined $30 \mathrm{hr}$ after insemination were at the two-cell stage. Thus, the accomplishment of the final stage of fertilization of the earlier penetrated eggs is obvious.

The incidence of polyspermy among penetrated eggs is presented in Table 2 . The polyspermic penetration through the zona pellucida was observed in 28.3 to $48.5 \%$ of the total penetrated eggs which had been inseminated with

Table 2. Polyspermic penetration following the insemination of preincubated rat epidymal spermatozoa

\begin{tabular}{|c|c|c|c|c|c|c|c|}
\hline \multirow{2}{*}{$\begin{array}{l}\text { Medium for } \\
\text { prein- } \\
\text { cubation } \\
\text { of sperm. }\end{array}$} & \multirow{2}{*}{$\begin{array}{l}\text { Prein- } \\
\text { cubation } \\
\text { time } \\
(h r)\end{array}$} & \multicolumn{6}{|c|}{$\begin{array}{c}\text { No. of eggs which had more than one spermatozoon inside the zona } \\
\text { and in the vitellus/no. of penetrated eggs after insemination } \\
\text { for: }\end{array}$} \\
\hline & & $3 h r$ & $4 h r$ & 5 to $6 \mathrm{hr}$ & 7 to $8 \mathrm{hr}$ & Total no. & $\%$ \\
\hline $\begin{array}{l}\text { Standard } \\
\text { medium }\end{array}$ & $\begin{array}{l}3^{\frac{1}{2}} \\
5 \frac{1}{2}\end{array}$ & $\bar{Z}$ & $\begin{array}{l}0 \\
0 / 1 \\
0 / 1\end{array}$ & $\begin{array}{c}20+0 / 64 \\
3+0 / 40 \\
0 / 4\end{array}$ & $\begin{array}{c}22+4 / 60 \\
6+2 / 37 \\
0 / 9\end{array}$ & $\begin{array}{c}42+4 / 124 \\
9+2 / 77 \\
0 / 14\end{array}$ & $\begin{array}{c}33 \cdot 9+3 \cdot 2 \\
11 \cdot 7+2 \cdot 6 \\
0\end{array}$ \\
\hline $\begin{array}{l}\text { Standard }+ \\
20 \% \text { rat } \\
\text { serum }\end{array}$ & $5 \frac{1}{\frac{1}{2}}$ & 二 & $\begin{array}{c}1+0 / 2 \\
0 / 2\end{array}$ & $\begin{array}{l}4+0 / 11 \\
2+0 / 17\end{array}$ & $\begin{array}{r}13+1 / 50 \\
7+1 / 30\end{array}$ & $\begin{array}{r}18+1 / 63 \\
9+1 / 49\end{array}$ & $\begin{array}{l}28 \cdot 6+1 \cdot 6 \\
18 \cdot 4+2 \cdot 0\end{array}$ \\
\hline $\begin{array}{l}\text { Standard }+ \\
2 \text { mM- } \\
\text { dGAMP }\end{array}$ & $\begin{array}{l}3^{\frac{1}{2}} \\
5 \frac{1}{2}\end{array}$ & $\begin{array}{l}\overline{0 / 6} \\
0 / 6\end{array}$ & $\begin{array}{l}0 / 1 \\
0 / 18 \\
-\end{array}$ & $\begin{array}{c}16+0 / 44 \\
2+1 / 21 \\
0 / 7\end{array}$ & $\begin{array}{l}49+13 / 89 \\
1+0 / 17 \\
-\end{array}$ & $\begin{array}{c}65+13 / 134 \\
3+1 / 62 \\
0 / 13\end{array}$ & $\begin{array}{c}48 \cdot 5+9 \cdot 7 \\
4 \cdot 8+1 \cdot 6 \\
0\end{array}$ \\
\hline $\begin{array}{l}\text { Standard } \\
\text { with high } \\
\mathrm{K} / \mathrm{Na} \text { ratio }\end{array}$ & $\begin{array}{l}3^{\frac{1}{2}} \\
5 \frac{1}{2}\end{array}$ & $\begin{array}{c}\overline{0} \\
3+0 / 19\end{array}$ & $\begin{array}{c}0 \\
0 / 7 \\
2+1 / 39\end{array}$ & $\begin{array}{l}5+1 / 30 \\
5+2 / 47 \\
2+1 / 43\end{array}$ & $\begin{array}{c}41+14 / 119 \\
16+5 / 77 \\
1+1 / 21\end{array}$ & $\begin{array}{c}46+15 / 149 \\
21+7 / 131 \\
8+3 / 122\end{array}$ & $\begin{array}{c}30 \cdot 9+10 \cdot 1 \\
16 \cdot 0+5 \cdot 3 \\
6 \cdot 6+2 \cdot 5\end{array}$ \\
\hline $\begin{array}{l}\text { Standard } \\
\text { with high } \\
\mathrm{K} / \mathrm{Na}+2 \mathrm{~mm} \\
\text { dCAMP }\end{array}$ & $\begin{array}{l}\frac{1}{2} \\
3 \\
5 \frac{1}{2}\end{array}$ & $\begin{array}{c}\overline{0} / 6 \\
15+6 / 78\end{array}$ & $\begin{array}{c}0 / 1 \\
14+2 / 36 \\
10+3 / 66\end{array}$ & $\begin{array}{r}7+4 / 28 \\
17+6 / 30 \\
8+5 / 65\end{array}$ & $\begin{array}{c}10+3 / 31 \\
6+2 / 23 \\
-\end{array}$ & $\begin{array}{l}17+7 / 60 \\
37+10 / 95 \\
33+14 / 209\end{array}$ & $\begin{array}{l}28 \cdot 3+11 \cdot 7 \\
39 \cdot 0+10 \cdot 5 \\
15 \cdot 8+6 \cdot 7\end{array}$ \\
\hline
\end{tabular}

$\frac{1}{2}$-hr preincubated spermatozoa. The rate of polyspermic penetration declined significantly with increasing periods of sperm preincubation, except for the experimental group preincubated in the presence of rat serum. In the last experimental group, where spermatozoa were preincubated in a medium with dGAMP and high $\mathrm{K} / \mathrm{Na}$ ratio, the difference was not significant between $\frac{1}{2}$ - and 3-hr preincubated samples, but the rate was significantly decreased in the $5 \frac{1}{2}$-hr preincubated sample. This indicates a decline in the fertilizing capacity of spermatozoa with increasing length of preincubation.

\section{DISCUSSION}

The rat is a suitable animal for the observation of sperm penetration into the eggs because of the long sperm tail and the relative transparency of rat ooplasm. Comprehensive descriptions of the early stages of fertilization in the rat by 
means of a phase-contrast microscope have been made by Austin (1951b) and Odor \& Blandau (1951). The tails of penetrating spermatozoa can be easily recognized either in fresh or in stained preparations. On the other hand, the acrosome of the rat spermatozoon is very thin, and the acrosome reaction is difficult to detect under a light microscope (Austin \& Bishop, 1958) but rat acrosomes can be observed by electron microscopy (Pikó, 1969).

In the present experiment, the advancement of the time of sperm penetration has been taken as a criterion of capacitation. This is based on the observations that rat spermatozoa require capacitation in the female tract (Austin, 1951a; Noyes, 1953). Austin (1951a) found that it took more than $4 \mathrm{hr}$ for the epididymal spermatozoa deposited into the ovarian bursa to start penetration of the zona pellucida. This was further investigated and led to the concept of capacitation (Austin, 1952), which was also discovered independently in the rabbit by Chang (1951). Noyes (1953) found that it took 7 to $8 \mathrm{hr}$ for the epididymal spermatozoa injected into the uterine lumen to penetrate the eggs, even though spermatozoa had reached the site of fertilization well before that time. This latency was distinctly longer than that of spermatozoa obtained from the uterus of females which had been mated 7 to $8 \mathrm{hr}$ previously.

The results presented here clearly show that the epididymal spermatozoa of the rat can be capacitated in vitro if preincubated in a suitable environment. This is in agreement with the observations which have been made in the hamster (Barros \& Austin, 1967; Yanagimachi, 1969), in the mouse (Iwamatsu \& Chang, 1969, 1970) and in the guinea-pig (Yanagimachi, 1972). The present result has also shown that supplementation with the secretions of the female reproductive tract is not required for the induction of capacitation, although this does not necessarily exclude the possibility that these secretions may act as a stimulant for the process of capacitation. Fertilization in vitro of the eggs with epididymal spermatozoa in a chemically defined medium is indeed a simplified model. The exact rôle of animal secretions for the facilitation of capacitation in vitro, however, has not been investigated.

The present study has shown the importance of the $\mathrm{K} / \mathrm{Na}$ ratio in the sperm incubation medium. Epididymal spermatozoa preincubated in a medium with high $\mathrm{K} / \mathrm{Na}$ ratio penetrated (a) more eggs, (b) sooner, than those preincubated in a medium with a low $\mathrm{K} / \mathrm{Na}$ ratio. It is known that the concentration of potassium and sodium is 37 and 115 mequiv., respectively, in the uterine fluid of pro-oestrous rats (Howard \& DeFeo, 1959). Thus, the $\mathrm{K} / \mathrm{Na}$ ratio in the uterine fluid (0.32) is about ten times higher than that of blood serum $(0.03)$ as confirmed by Ringler (1961). It is of interest that the high $\mathrm{K} / \mathrm{Na}$ ratio used in the present experiment is equal to the $\mathrm{K} / \mathrm{Na}$ ratio in the uterine fluid of pro-oestrous rats. Although a possible physiological rôle of the high $\mathrm{K} / \mathrm{Na}$ ratio in the uterine fluid was suggested for ovum implantation (Clemetson, Mallikarjuneswara, Moshfeghi, Carr \& Wilds, 1970), this seems unlikely because of the lapse of several days between pro-oestrus and the time of implantation. Since a high $\mathrm{K} / \mathrm{Na}$ ratio afforded an efficient environment for the capacitation of spermatozoa as revealed in the present study, the physiological significance of a high $\mathrm{K} / \mathrm{Na}$ ratio in the uterine fluid of pro-oestrous rats can be adequately interpreted for the first time. 
The mechanism(s) by which a high $\mathrm{K} / \mathrm{Na}$ ratio exerts a favourable effect on spermatozoa is not clear at present, but the epididymal fluid and the semen are also known to have a high $\mathrm{K} / \mathrm{Na}$ ratio, and this is considered to be related to the long survival of the spermatozoa in the male reproductive tract (Mann, 1964). The loss of motility due to extensive dilution of ram and bull spermatozoa can be partially prevented by the addition of potassium to the suspension medium (Blackshaw, 1953; White, 1953). Although the intracellular $\mathrm{K} / \mathrm{Na}$ ratio in the spermatozoa is higher than that of the seminal plasma (Mann, 1964), the difference is far less marked than that between the extracellular fluid and the somatic cells such as red blood cells, nerve cells and muscle fibres (Kernan, 1965). Sperm cells appear to be less efficient in concentrating potassium intracellularly and expelling sodium ions from the cell membrane. This is supported by the presence of a high $\mathrm{K} / \mathrm{Na}$ ratio in the head and a low $\mathrm{K} / \mathrm{Na}$ ratio in the tail of some invertebrate spermatozoa (Steinbach \& Dunham, 1962). It is considered that the high $\mathrm{K} / \mathrm{Na}$ ratio in the medium may prevent leakage of potassium from the sperm cells, thus maintaining the intracellular level of potassium for cellular activity. Even if this is a good reason for a better maintenance of fertilizing capacity, how the spermatozoa are capacitated in a medium with a high $\mathrm{K} / \mathrm{Na}$ ratio still cannot be explained at present.

The mode of action of dibutyryl cyclic AMP seems to be different from that of a high $\mathrm{K} / \mathrm{Na}$ ratio and it is not related to the concentration of potassium since the preincubation of spermatozoa in the presence of dCAMP caused significant advancement of sperm penetration in both low and high $\mathrm{K} / \mathrm{Na}$ ratio.

It is known that the capacitation of spermatozoa, at least in the rabbit, is under hormonal control; capacitation occurs efficiently in the uterus of oestrous rabbits or rabbits treated with oestrogen, but does not occur, or occurs less efficiently, under the influence of progesterone (Chang, 1969). It is not known, however, how these steroids exert their influence on spermatozoa and there is no concrete evidence for the direct action of these steroids on spermatozoa.

The mechanism of action by cyclic AMP for sperm capacitation, especially concerning the nucleotide specificity, cannot be adequately postulated from the present study. Nevertheless, it is known that (1) phosphodiesterase inhibitors or cyclic AMP administered exogenously caused a marked increase in the respiration and motility of bull spermatozoa (Garbers, Lust, First \& Lardy, 1971), (2) there is an adenyl cyclase system in the spermatozoa of seaurchin, dog and man (Hardman, Hammer, Hoos \& Sutherland, 1971), and monkey (Casillas \& Hoskins, 1971) and that (3) a decrease of ATP occurred during the capacitation of hamster spermatozoa in vitro (Upchurch \& Morton, 1972). It may be inferred, therefore, that the activation of the adenyl cyclase system in the sperm cells might trigger the process of capacitation. The exogenously administered cyclic AMP might produce the same effect, thus accelerating the process of capacitation.

A decrease of polyspermic penetration was observed by increasing the time of preincubation of spermatozoa even in a medium that induced fast sperm capacitation (Table 2). This is in contrast to the previous experiments where the 
incidence of polyspermy was higher in mouse eggs penetrated by preincubated spermatozoa (Iwamatsu \& Chang, 1970; Toyoda et al., 1971). Data presented in Tables 1 and 2 may indicate a positive correlation between overall penetration rates and the incidence of polyspermy among different experimental groups during various periods of preincubation. It is possible that the media employed in the present study are still not satisfactory enough for maintenance of the fertilizing capacity of spermatozoa, even though capacitation was better achieved, because prolonged incubation decreased the penetration rate. The earlier penetration by preincubated spermatozoa may be responsible, at least in part, for the reduction of polyspermy because the eggs were penetrated at an earlier stage when the zona reaction was more efficient. A high incidence of polyspermy has been a common feature of those instances of fertilization in vitro so far reported in the hamster (Yanagimachi \& Chang, 1964), mouse (Iwamatsu \& Chang, 1970), and rat (Miyamoto \& Chang, 1973; Toyoda \& Chang, 1974). It is not known whether such a high incidence is simply due to a high concentration of spermatozoa in the fertilization medium.

\section{ACKNOWLEDGMENTS}

One of us (M.C.C.) was a Research Career Awardee (K6-HD 18,334) of the National Institute of Child Health and Human Development.

This work was supported by grants (HD 03472 and GM 14370) from the Public Health Service and a grant from the Ford Foundation. Thanks are due to Mrs Virginia Kelleher for assistance.

\section{REFERENGES}

Austrin, C. R. (1951a) Observation on the penetration of the sperm into the mammalian egg. Austr. $\mathcal{F}$. scient. Res. 4, 581.

Austin, G. R. (1951b) The formation, growth, and conjugation of the pronuclei in the rat egg. $\mathcal{F}$. R. microsc. Soc. 71, 295.

Austin, G. R. (1952) The capacitation of mammalian sperm. Nature, Lond. 170, 326.

Austin, G. R. \& Bishop, M. W. H. (1958) Role of the rodent acrosome and perforatorium in fertilization. Proc. R. Soc. B, 149, 241.

Barros, C. \& Austin, C. R. (1967) In vitro fertilization and sperm acrosome reaction in the hamster. 7. exp. Zool. 166, 317.

Barros, C. \& Garavagno, A. (1970) Capacitation of hamster spermatozoa with blood sera. F. Reprod. Fert. 22, 381.

BAvister, B. D. (1969) Environmental factors important for in vitro fertilization in the hamster. $\mathcal{F}$. Reprod. Fert. 18, 544.

Biggers, J. D., Whitten, W. K. \& Whitringham, D. G. (1970) The culture of mouse embryos in vitro. In: Methods in Mammalian Embryology, pp. 86-116. Ed. J. G. Daniel, Jr. Academic Press, New York.

Bt.ACKshaW, A. W. (1953) The effects of potassium and calcium salts on the motility of ram, rabbit and bull spermatozoa. F. Physiol., Lond. 120, 465.

Casillas, E. R. \& Hoskins, D. D. (1971) Adenyl cyclase activity and cyclic 3',5'-AMP content of ejaculated monkey spermatozoa. Archs Biochem. Biophys. 147, 148.

Chang, M. C. (1951) Fertilizing capacity of spermatozoa deposited into the Fallopian tubes. Nature, Lond. 168, 697.

Chang, M. C. (1969) Hormonal regulation of sperm capacitation. In: Advances in the Biosciences, Vol. 4, p. 13. Ed. G. Raspé. Pergamon Press, Vieweg.

Clemetson, G. A. B., Mallikarjuneswara, V. R., Moshfeghi, M. M., Garr, J. J. \& Wilds, J. M. (1970) The effect of oestrogen and progesterone on the sodium and potassium concentrations of rat uterine fluid. F. Endocr. 47, 309. 
Garbers, D. L., Lust, W. D., First, N. L. \& Lardy, H. A. (1971) Effects of phosphodiesterase inhibitors and cyclic nucleotides on sperm respiration and motility. Biochemistry, 10, 1825.

Hardman, J. G., Hammer, J. L., Hoos, R. T. \& Sutherland, E. W. (1971) Adenyl cyclase, phosphodiesterase, and cyclic AMP of human sperm and seminal plasma. Fedn Proc. Fedn Am. Socs exp. Biol. 30, 1251.

Howard, E. \& DeFeo, V. J. (1959) Potassium and sodium content of uterine and seminal vesicle secretions. Am. J. Physiol. 196, 65.

Iwamatsu, T. \& Chang, M. G. (1969) In vitro fertilization of mouse eggs in the presence of bovine follicular fluid. Nature, Lond. 224, 919.

Iwamatsu, T. \& Ghang, M. C. (1970) Further investigation of capacitation of sperm and fertilization of mouse eggs in vitro. 7. exp. Zool. 175, 271.

Kernan, R. P. (1965) Cell K. Appleton-Century-Crofts, New York.

MANN, T. (1964) The biochemistry of semen and of the male reproductive tract. Wiley, New York.

Mryamoto, H. \& Chang, M. G. (1972) Development of mouse eggs fertilized in vitro by epididymal spermatozoa. 7. Reprod. Fert. 30, 135.

Miyamoto, H. \& Chang, M. C. (1973) Fertilization of rat eggs in vitro. Biol. Reprod. (in press).

Noyes, R. W. (1953) The fertilizing capacity of spermatozoa. Western 7. Surg. Obstet. Gynec. $61,342$.

Odor, D. L. \& Blandau, R. J. (1951) Observations on fertilization and the first segmentation division in rat ova. Am. 7. Anat. 89, 29.

Pı́ó, L. (1969) Gamete structure and sperm entry in mammals. In: Fertilization, Vol. 2, Chap. 18. Eds. C. B. Metz and A. Monroy. Acacemic Press, New York.

RiNGLer, I. (1961) The composition of rat uterine fluid. Endocrinology, 68, 285.

Steinbach, H. B. \& Dunham, P. B. (1962) Ionic balance of sperm cells. In: Spermatozoan Motility. Ed. D. W. Bishop. Am. Assoc. Adv. Sci. Publ. No. 72, Washington.

Toyoda, Y. \& Ghang, M. G. (1974) Fertilization of rat eggs in vitro by epididymal spermatozoa and the development of the eggs following transfer. 7 . Reprod. Fert. 36, 9.

Toyoda, Y., Yokoyama, M. \& Hosi, T. (1971) Studies on the fertilization of mouse eggs in vitro. Jap. 7. Anim. Reprod. 16, 147.

Upchurch, B. J. \& Morton, B. E. (1972) ATP levels in hamster spermatozoa during capacitation in vitro. Abstract No. 92. Society for the Study of Reproduction, 5th Meeting, East Lansing, Michigan.

White, I. G. (1953) Metabolic studies of washed and diluted ram and bull spermatozoa. Austr. 7 . biol. Sci. 6, 706 .

YaNAGmachi, R. (1969) In vitro capacitation of hamster spermatozoa by follicular fluid. $\mathcal{F}$. Reprod. Fert. 18, 275.

Yanagmachr, R. (1970) In vitro capacitation of golden hamster spermatozoa by homologous and heterologous blood sera. Biol. Reprod. 3, 147.

Yanagmaghi, R. (1972) Fertilization of guinea pig eggs in vitro. Anat. Rec. 174, 9.

Yanigrmachi, R. \& Ghang, M. G. (1964) In vitro fertilization of golden hamster ova. 7. exp. Zool. 156, 361. 